\title{
The Research of Liberal Arts Practice Teaching Mode Based on Cyber Role- Play
}

\author{
Meifang Chen ${ }^{1}$ Yan $\mathrm{Li}^{1}$ \\ ${ }^{1}$ Jiangxi Science and Technology Normal University
}

\begin{abstract}
With the arriving era of Chinese popular higher education, the students majored in liberal arts have to obtain more and more practical skills and the development of applied arts majors has taken more and more attention. In order to adapt the development trend of liberal arts talent training in the new age, each college actively explores the talent training scheme for arts students, increases practical training dynamics, and finally promotes practical ability of them. This paper makes use of the existing digital comprehensive experimental teaching platform, actively explores the mode reform of arts practice teaching. Cyber role-play has been introduced in the process of practice teaching to improve the quality of experimental teaching.
\end{abstract}

Keywords: The comprehensive experimental center of liberal arts; Cyber roleplay; Experimental teaching mode formatting

\section{Introduction}

In the traditional talent training for liberal arts students, professional practice teaching has been neglected. All universities have obviously paid insufficient attention to the training of practical ability for liberal arts students and the students also lack of learning initiative. No matter in aspects of teachers or hardware equip- ments, they are relatively weak. In 2008, with the first liberal arts laboratory becoming "the national experimental teaching demonstration center", each university began with "the construction of national experimental teaching demonstration center " as the driving force, took the goal of improving the liberal arts students' practical ability, and greatly promoted the development of comprehensive teaching experiment center for liberal arts. With the main methods of opening experiment practice resources and sharing resources, they have positively constructed the experiment and practice teaching environment of "learn to meet practical meets, practice to promote learning, and combine learning with practicing together".

However, as the main means to improve students' practice application ability and innovation ability, the effect of college practice teaching is below expectation. The traditional experimental objects of science and engineering are relatively stable. The teaching steps request students to finish experiment according to class plan requirements. The experiment can be repeated under the control of certain condition, and constantly verified. But in the domain of humanities and social sciences, the condition is totally different. The objects are in the process of changing, so the experiment cannot be repeated as that in science and engineering. What's more, all disciplines integrated and infiltrated with each other, and more and more liberal arts experiment 
courses have been carried out when various disciplines share the achievements and make full use of technological means to promote the development of science.

\section{The existing problems of liberal arts practice teaching mode in col- lege at present}

\subsection{The experiment teaching steps has been neglected in the cur- riculum setting}

Through the observation of teaching and training program for each major in the liberal arts department, it's easy to find that some teaching schedules are unreasonable. They focus on theoretical study of the liberal arts, but ignore the practice operation skills. Practice classes didn't even account for $30 \%$ of all, so the students' practical ability can't get sufficient exercise and improvement.

In recent years, the practice training problems of liberal arts began to be taken seriously. Directly leading by educational administration departments, some colleges have made some hard rules in curriculum setting, which greatly improved practical courses rate of the liberal arts. However, although the experiment courses are opened up, there are still some problems existing. In fact, teachers give practice teaching lessons not according to the standard. They directly present the lessons like giving some ordinary theory courses or they demonstrate by themselves, but the students have no chance to practice.

\subsection{The experimental resources are limited, and the teaching envi- ronment is one-sided}

In the past, much simulation experimental software was standalone version and the IP bound was set. One single computer could only login the corresponding client. Once the hardware resources damaged, the client couldn't continue to use.
Standalone version software could only be used under single user mode. It lacked of exchange and cooperation between companions. Its content was unalterable and couldn't adapt to the variety of work situation in reality, so lacked of its simulation.

The construction of experimental software resources was also ignored. More attention had been paid on quantity than quality. Not only the updating cycle was very long, but also it couldn't adapt to the outside world changes, which had serious impact on the quality of practice teaching.

2.3. The practice teaching mode is conservative, and the teaching methods are simple

In practical experiment teaching, teachers often take the similar teaching method used in science and engineering experiment teaching. Before the experiment, they give a detailed explanation for the experimental content, demonstrate the experimental steps carefully, and reiterate the key and difficult points. They try to make the students get the ideal, correct experimental results through their presentation. The experiment teaching is teacher-centered. Teachers take control in the whole experiment. They arrange students experimental progress, experimental content, experimental steps, and set the experimental results. Students just need to operate according to the manual instructions, and then they can finish the experiment project. This method goes against students' active participation. The teaching method is very simple, mainly teachers' teaching and demonstration.

\subsection{The teacher's team is weak, and the practice teaching concept is old}

The task of liberal arts experiment teaching is to combine teaching content and characteristics of different liberal arts subjects, to use multimedia, computers, and other advanced equipments and 
teaching means to systematically analyze the information, then to construct a virtual environment to emulate, simulate, apply and innovate, so as to solve all kinds of problems in modern domain of humanism science or related areas. At present, the liberal arts experiment teaching is taken charge of by the theoretical teacher, and the requirements for them are very high. But there are some problems existing in management level or teachers themselves.

First of all, the practice conception is too old. The managers or even some teachers get inadequacy understanding of experimental teaching. They take no account of it and muddle through their work. For example, in accounting class hours of experiment teaching, there is a discount in many colleges, that is, practice class hours only count $70 \%$ of normal or even lower percentage. This greatly reduces the enthusiasm of practice teachers and influences them of the real open rate of practice teaching. Even worse, practice teachers still use traditional teaching mode, result that the class obviously can't get satisfactory teaching effect.

In addition, the request for teachers is rather high, but teacher's team is weak. Liberal arts experiment teaching not only requires teachers to grasp the concept knowledge and practical skills of experiment course, but also to master modern educational technology. However, on the one hand, due to long-term impact from traditional education model, the practice teaching has been keeping the assistant position, which makes young teachers reluctant to work in laboratory room. On the other hand, the teaching phenomenon is bad. The existing teachers are also not willing to dig into new technology and they lack of practice skills. All these go against talents training target of higher education.

\subsection{Resource management does not reach the designated position, so that resources can not be shared and efficiently used}

The majority of liberal arts experimental resources scattered in each different liberal arts college. The laboratory management personnel are always administrative staff or professional teachers concurrently who lack of systematic equipment management and maintenance experience. The laboratory is only opened to the college itself or some of departments, which goes against resources sharing and utilizing. At the same time, because every college doesn't share the laboratory, the problem of repeat resources construction exists inevitably, influencing effective utilization of resources.

\section{The application of cyber role-play in liberal arts experimental teach- ing mode}

In the traditional mode of experimental teaching, teachers have become the center of teaching. It is difficult to develop students' activity and enthusiasm. With constant exploration of practice teaching mode, the market becomes more and stricter to screen for talents. The existing practice teaching mode can't adapt to the development trend of future teaching. Just only by changing the traditional single teaching mode, replacing the mode of teacher as the main body with the one of student as the main body, liberal arts talents can be cultivated in the new age.

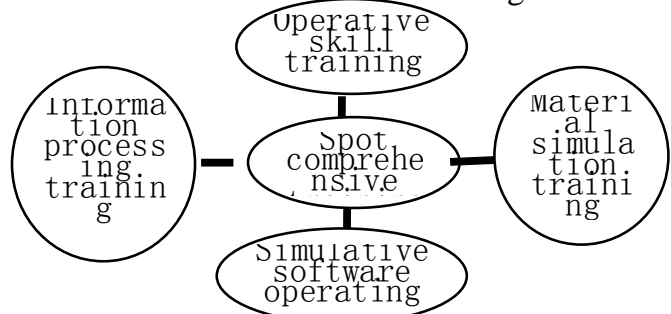

Fig. 1: Multiple experimental teaching modes. 
The teaching mode taking student as the main body combine with various practice training methods to cultivate students' autonomy, including operative skill training, material simulation training, simulative software operating, and information processing training. The four training methods are unfolded around spot comprehensive training. Based on the simulated actual scene, they combine theory with practice, and make students immerse in a virtual scene by playing certain social role.

The so-called cyber role-play, as an important strategy in cooperative learning, comes from virtual games. It refers that individual has the condition to play certain social role, undertakes and reproduces the role's processes and activities. In liberal arts practice teaching activities, cyber role-play penetrates in all sorts of practice teaching training.

\subsection{Operative skill training}

Operative skill training mainly aims to cultivate students' manual operation ability. It is the study of various materials made by hand. In the practice curriculum of liberal arts, the operative skill training can be used to display finished works, such as finished products of photographic works, accountants' handmade accounts, and manual games of preschool education and so on. In the process of making finished products, students play the role of photographers, accountants, kindergarten teachers, etc. They not only experience different social positions, but also exercise their practical skills.

\subsection{Material simulation training}

Material simulation training can be used in practical training of stream, economic management, trade and other industries. Sand table simulation is a typical example. It is directed against the modern advanced enterprise operation and management technology which is ERP (Enterprise Resource Planning System) and simulates all the key links of enterprise operating, to train team spirit, improve management abilities. In the training, every student of the team is designed with different functional role. And the students participate in the whole training process, greatly improving their interests in learning.

\subsection{Simulative software operating}

Simulative software includes both singleuser operation software and multi-user collaborative software. In multi-user collaborative software, cyber role-play penetrates in the whole process. When learners use the software, they will be assigned a role according to the rules of software setting. The role will be assigned some learning task. When the role completes the task, certain incentives will be given to motivate learners' constant progress.

\subsection{Information processing ability}

In liberal arts experiment teaching procedure, modern information technology plays an important role in showing results and completing tasks. The learners must have information literacy and obtain certain information processing ability to recreate data. In team learning, every member should possess information processing ability, because they need to use modern information technology to help completing the task when they play different roles in presenting achievements and completing tasks, according to the labor division.

\section{The liberal arts practical teaching mode based on cyber role-play}

Students, as the key role in practical teaching of liberal arts, often are ignored during traditional teaching. But it is very different in the cyber role-play, where students are strongly considered as key role. By this way, it is very useful to encourage student to engage in simulative activities, such as social work and team 
cooperation, so as to improve their social

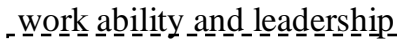

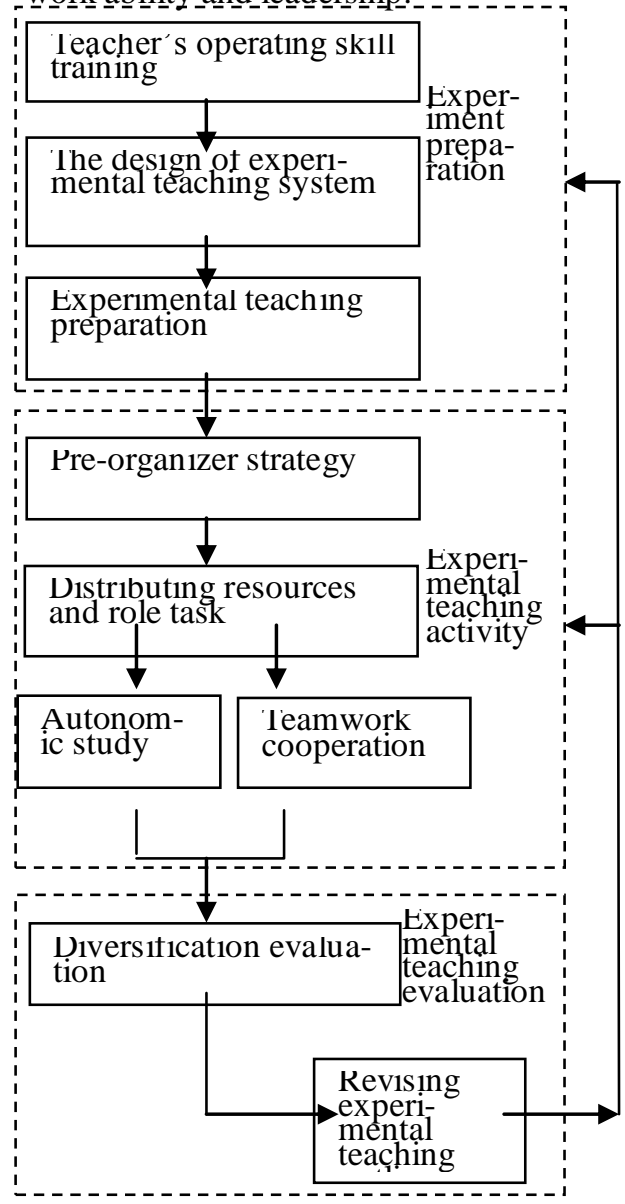

Fig. 2: Multiple experimental teaching modes.

The liberal arts practical teaching mode based on cyber role-play consists of three main parts: experiment preparation, experimental teaching activity and experimental teaching evaluation.

\subsection{Experiment preparation}

Experiment preparation mainly includes the preparation of teacher's personal practice skills, practical teaching courses, tools and equipments. Before the experiment, the teacher should understand the environment of the laboratory, and be familiar with the operation of equipments and software. In order to guarantee the effect of the experiment, all of the teachers must be trained before actual activities. The design of practical teaching is the connection of practical theories and actual practical teaching aimed at the practical lessons. The experiment teaching preparations focus on the resources and surrounding, including making sure the equipments in place, creating good atmosphere and providing assorted experimental materials, etc.

\subsection{Experimental teaching activity}

The experimental teaching activity is the center of experimental teaching mode. Teachers make use of the pre-organizer strategy to give students thinking direction, to make sure the students understand the main task and background of this experiment, then analyze roles and recourses according to system design. Students can switch role between autonomic study and teamwork cooperation. With each method under the guidance of teachers, Students set their own learning goals and schedules themselves. Teachers play as tutors, guiding students to finish the experiment.

\subsection{Experimental teaching evalua- tion}

In the liberal arts practical teaching mode based on cyber role-play, the teaching evaluation also differs from traditional one. The differences include the object, the scope and the method of the evaluation. Traditionally, the teacher plays as the main part, as well as the object during the evaluation in experimental teaching. But in practice courses based on cyber role-play, students play the role as valuators the same as teachers. In the scope of evaluation, it's beyond the classroom. Using with the network platform of experimental teaching, it can provide an opening evaluating environment. Besides, because of the various contents of evaluation, such as written material and multi- 
media material, the evaluation methods also become relatively diverse.

\section{Conclusion}

The liberal arts practical teaching mode based on cyber role-play emphasizes more on students' actively participating. It aims at improving students' learning enthusiasm, fully making students from passive to active, and fully exercising students' abilities of thinking and problem-solving to avoid training to blindly imitative robots. At the same time, it cultivates students' team spirit and decisionmaking skills and promotes students' ability.

\section{References}

[1] Huidong Shu, "Innovation research on liberal arts experimental teaching mode under the perspective of knowledge management", Experimental Technology and Management,2010, (5)

[2] Jiusheng Yuan, "The reform and innovation of liberal arts experimental teaching", Concept Review,2011,(10)

[3] "The design and experiment of liberal arts experimental teaching and management system based on Web", China educational informationization,2011,(3).

[4] Yang Song, "Research on experimental teaching quality and security system of liberal arts at university", China Electric Power Education,2009,(9).

[5] Yunyan Zhong, Xinfeng Zhang, Research on experimental teaching mode based on the humanistic learning theory $[\mathrm{J}]$ Journal of Guangdong Technology Normal University( Natural Science Edition) ,2010,(3). 